\title{
No evidence of inbreeding depression in fast declining herds of migratory caribou
}

\author{
Marianne Gagnon $^{1}$ (D) | Glenn Yannic ${ }^{2}$ (D) | Charles Perrier ${ }^{3}$ | Steeve D. Côté ${ }^{1}$ (D)
}

${ }^{1}$ Département de Biologie, Caribou Ungava and Centre d'Études Nordiques, Université Laval, Quebec, QC, Canada

${ }^{2}$ CNRS, LECA, Université Grenoble Alpes, University Savoie Mont Blanc, Grenoble, France

${ }^{3}$ CEFE UMR 5175, CNRS, Université de Montpellier, Université Paul Valery Montpellier, Montpellier, France

\section{Correspondence}

Marianne Gagnon, Département de Biologie, Caribou Ungava and Centre d'Études Nordiques, Université Laval, 1045 avenue de la Médecine, Quebec, QC G1V 0A6, Canada. Email: marianne.gagnon.6@ulaval.ca

Glenn Yannic, CNRS, LECA, Univ. Grenoble Alpes, Univ. Savoie Mont Blanc, 38000

Grenoble, France.

Email: glenn.yannic@univ-smb.fr

Funding information

Natural Sciences and Engineering Research Council of Canada; Caribou Ungava;

Ministère des Forêts, de la Faune et des Parcs; Labex; Fonds de Recherche Nature et Technologies du Québec

\begin{abstract}
Identifying inbreeding depression early in small and declining populations is essential for management and conservation decisions. Correlations between heterozygosity and fitness (HFCs) provide a way to identify inbreeding depression without prior knowledge of kinship among individuals. In Northern Quebec and Labrador, the size of two herds of migratory caribou (Rivière-George, RG and Rivière-aux-Feuilles, RAF) has declined by one to two orders of magnitude in the last three decades. This raises the question of a possible increase in inbreeding depression originating from, and possibly contributing to, the demographic decline in those populations. Here, we tested for the association of genomic inbreeding indices (estimated with 22,073 SNPs) with body mass and survival in 400 caribou sampled in RG and RAF herds between 1996 and 2016. We found no association of individual heterozygosity or inbreeding coefficient with body mass or annual survival. Furthermore, those genomic inbreeding indices remained stable over the period monitored. These results suggest that the rapid and intense demographic decline of the herds did not cause inbreeding depression in those populations. Although we found no evidence for HFCs, if demographic decline continues, it is possible that such inbreeding depression would be triggered.
\end{abstract}

\section{KEYWORDS}

general effect hypothesis, heterozygosity-fitness correlation, inbreeding depression, migratory caribou, Rangifer tarandus, SNP

\section{1 | INTRODUCTION}

Inbreeding depression, the reduced fitness of inbred individuals (Charlesworth \& Charlesworth, 1987), can contribute to genetic Allee effects, a positive correlation between population size and fitness (Luque et al., 2016; Wittmann, Stuis, \& Metzler, 2018), and can hence increase the risk of extinction of small and/or declining populations. Because inbred individuals have an increased probability of expressing recessive deleterious mutations or homozygous genotypes at over-dominant genes (Charlesworth \& Charlesworth, 1987), they usually have low survival (Cecchi, Giacalone, \& Paci,
2016; Norén, Godoy, Dalén, Meijer, \& Angerbjörn, 2016), reproduction (Norén et al., 2016) and/or poor body condition (Brommer, Kekkonen, \& Wikström, 2015; Gholizadeh \& Ghafouri-Kesbi, 2016). Lower values of life-history traits can in turn affect population growth (Gaillard, Festa-Bianchet, Yoccoz, Loison, \& Toïgo, 2000). In a conservation context, it is thus essential to identify inbreeding depression early in a population and to understand how it affects individual fitness to avoid extinction vortexes (Gilpin \& Soulé, 1986; Tanaka, 1997, 1998, 2000).

Inbreeding depression is traditionally studied with the help of exhaustive pedigrees, requiring long-term monitoring of populations 
and extensive knowledge of many kinship relations among individuals (Cecchi et al., 2016; Norén et al., 2016; Silió, Barragán, Fernández, García-Casco, \& Rodríguez, 2016). Although this approach directly assesses inbreeding, it is costly and often unrealistic to produce pedigrees for natural populations (but see Charmantier, Garant, \& Kruuk, 2014). Because inbreeding increases genome-wide homozygosity (Wright, 1977), it is frequently assumed that individual heterozygosity can be used as a proxy for inbreeding level (Balloux, Amos, \& Coulson, 2004; Miller et al., 2014). Heterozygosity-fitness correlations (HFCs) have thus become an appealing tool in conservation and evolutionary biology to indirectly detect inbreeding depression, without prior knowledge of kinship among individuals (Chapman, Nakagawa, Coltman, Slate, \& Sheldon, 2009; Coltman \& Slate, 2003; Hoffman et al., 2014). The rationale behind this approach is that a positive correlation between heterozygosity and fitness should appear when inbreeding depression affects a portion of the individuals in a population. In such cases, inbred individuals will have lower fitness as direct results of decreasing heterozygosity, whereas noninbred individuals will present higher heterozygosity and then higher fitness (general effect hypothesis; David, Delay, Berthou, \& Jarne, 1995). Yet, recent studies have shown that genomic measures of relatedness better approximate pedigree-based inbreeding in comparison with multi-locus heterozygosity (Bérénos, Ellis, Pilkington, \& Pemberton, 2014; Huisman, Kruuk, Ellis, CluttonBrock, \& Pemberton, 2016; Kardos, Taylor, Ellegren, Luikart, \& Allendorf, 2016). For instance, inbreeding coefficients based on measures of genomic relatedness such as $F_{\text {grm }}$ (Huisman et al., 2016; $F^{\prime \prime I}$ in Yang, Lee, Goddard, \& Visscher, 2011) that gives more weight to homozygosity of rare alleles proved to correlate well with fitness traits such as breeding success or offspring survival, even more so than pedigree-based inbreeding coefficients (Huisman et al., 2016).

Studies that have investigated the relationship between individual heterozygosity, as a proxy for inbreeding, and fitness usually found contrasted results (Chapman et al., 2009; Szulkin, Bierne, \& David, 2010). In some cases, it has been shown that heterozygosity was positively associated with fitness- or performance-related traits (Brambilla, Biebach, Bassano, Bogliani, \& von Hardenberg, 2015; Da Silva et al., 2009; Herdegen, Nadachowska-Brzyska, Konowalik, Babik, \& Radwan, 2013; Hoffman et al., 2014) and those results were attributed to the general effect hypothesis (David et al., 1995). The general effect hypothesis posits that inbreeding is negatively correlated with (a) fitness and (b) genetic diversity (Slate et al., 2004; Szulkin et al., 2010). If the former assumption is broadly accepted (Allendorf, Aitken, \& Luikart, 2013; Brommer et al., 2015; Charlesworth \& Charlesworth, 1987; Norén et al., 2016), the later is still debated (Balloux et al., 2004; DeWoody \& DeWoody, 2005; Miller et al., 2014). Indeed, it is argued that marker-based estimates of genetic diversity should reflect genome-wide diversity and that it requires at the very least a few hundreds genetic markers to properly assess global diversity (Balloux et al., 2004; DeWoody \& DeWoody, 2005; Miller et al., 2014). Yet, HFC studies were until recently only based on a few microsatellite markers, usually between 5 and 15 loci (Coltman \& Slate, 2003), as a surrogate of genome-wide diversity
(Da Silva, Luikart, Yoccoz, Cohas, \& Allainé, 2006; Herdegen et al., 2013; Velando, Barros, \& Moran, 2015). Instead of demonstrating the effect of genome-wide diversity on fitness, those HFCs may result from the direct effect of diversity at functional loci or from local effect of fitness-related loci linked to the markers used to estimate diversity (direct or local effect hypothesis; David et al., 1995; David, 1998). Besides, some studies on HFCs using microsatellites showed that the diversity of only a few markers was associated with performance-related traits, providing support to the local effect hypothesis rather than the general effect hypothesis (García-Navas, Cáliz-Campal, Ferrer, Sanz, \& Ortego, 2014; Guinand et al., 2013; Lieutenant-Gosselin \& Bernatchez, 2006). The advent of next-generation sequencing techniques may facilitate the production of detailed studies on HFCs by giving access to many thousands single nucleotide polymorphisms (SNPs) at a relatively low cost, allowing accurate measures of genomic relatedness and heterozygosity (Hoffman et al., 2014; Huisman et al., 2016; Kardos et al., 2016; Miller et al., 2014; Mitchell, Vitikainen, Wells, Cant, \& Nichols, 2017).

In Northern Quebec and Labrador (Canada), Rivière-George (RG) and Rivière-aux-Feuilles (RAF) herds of migratory caribou (Rangifer tarandus; called reindeer in Eurasia) have experienced a marked demographic decline starting in the 1990s and 2000s and still ongoing (around 5-7 generations, respectively; Quebec ministère des Forêts, de la Faune et des Parcs [MFFP], unpublished). RG herd increased from 61,842 individuals in 1963 (Des Meules \& Brassard, 1964) to $823,000 \pm 104,000$ individuals in 1993 (Couturier, Courtois, Crépeau, Rivest, \& Luttich, 1996). Then, it declined to $8,900 \pm 668$ individuals in 2016 (MFFP, unpublished), approximating a 99\% decline in 23 years. For the RAF herd, it went from 56,000 individuals (Le Hénaff, 1976) to more than 628,000 individuals $(1,193,000 \pm 565,482$; Couturier, Jean, Otto, \& Rivard, 2004) between 1975 and 2001. It then decreased by about $70 \%$ to reach 199,000 ( $\pm 15,920)$ individuals in 2016 (MFFP; unpublished; Figure 1). Although the census sizes of RG and RAF herds are still relatively large compared to populations usually subjected to inbreeding depression (Blomqvist, Pauliny, Larsson, \& Flodin, 2010; Norén et al., 2016; Velando et al., 2015), certain mechanisms can reduce the effective size of these populations (i.e. the true number of effective breeders; Wright, 1931) and increase the risk of inbreeding. For instance, caribou is a polygynous species (L'Italien et al., 2012) that displays large variations of reproductive success generated by environmental (Couturier, Côté, Otto, Weladji, \& Huot, 2009b) and individual heterogeneity (Pachkowski, Côté, \& Festa-Bianchet, 2013), which can have such effect (Balloux et al., 2004; Wright, 1931). In addition, it has been shown that reindeer females do not avoid inbreeding when choosing a mating partner (Holand et al., 2007). Given the abrupt decline of RG and RAF herds and that caribou display characteristics that could increase inbreeding risk, it raises the question of whether inbreeding could have increased in the last decades and hence affected individual fitness in those populations, through inbreeding depression, and contributed further to their decline.

Here, we tested for a potential association between genomic inbreeding indices and two performance traits, body mass and annual 

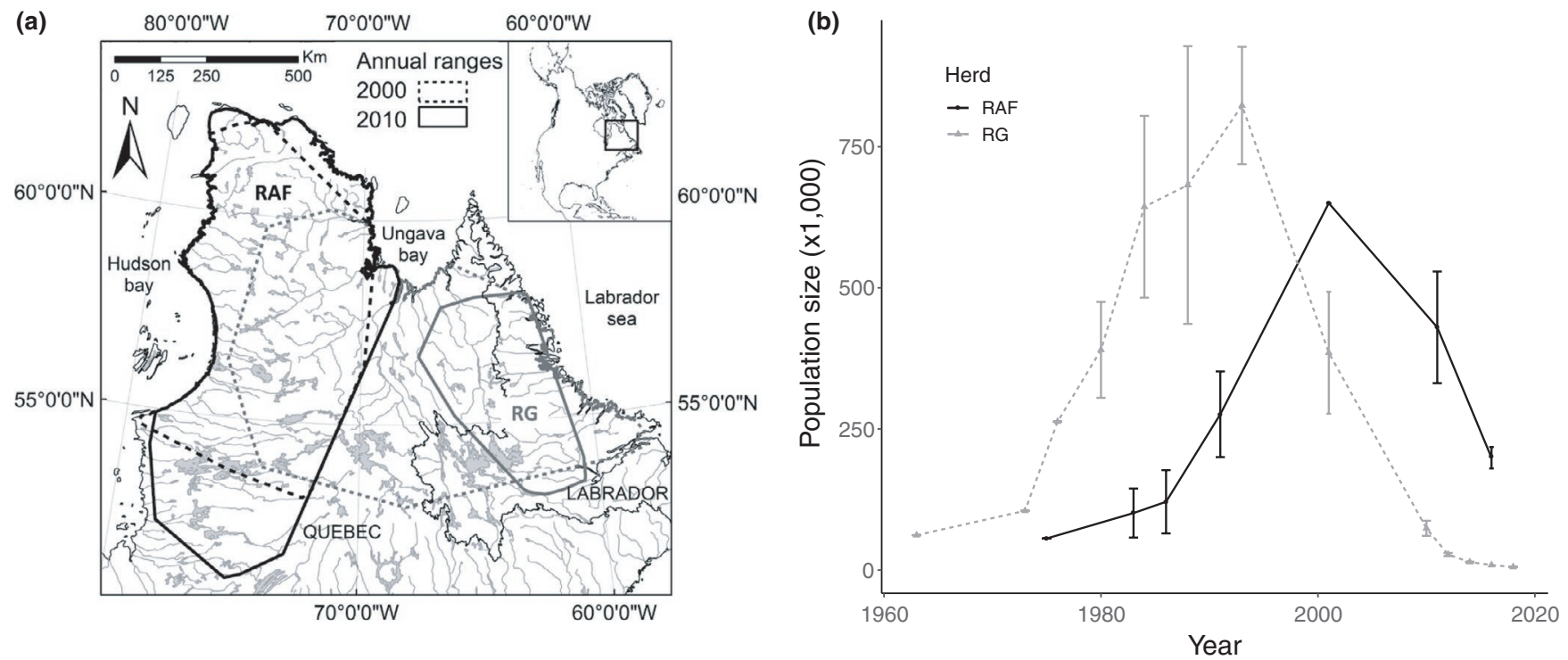

FIGURE 1 (a) Annual ranges of the Rivière-George (RG) and Rivière-aux-Feuilles (RAF) migratory caribou (Rangifer tarandus) herds, located in northern Québec and Labrador. We delineated ranges using 100\% minimum convex polygons based on ARGOS locations collected on 54 females for RG and 60 females for RAF in 2010. (b) Population sizes of RG and RAF herds. Population sizes were estimated based on aerial surveys (MFFP). Their confidence intervals $(90 \% \mathrm{Cl})$ were computed using a number of parameters recorded during surveys and are inherent to the method

survival, in two declining herds of migratory caribou. Standardized multi-locus heterozygosity (sMLH) and $F_{\text {grm }}$ ( $F^{\text {III }}$ in Yang et al., 2011) were estimated using 22,073 SNPs obtained by double-digest restriction-site-associated DNA sequencing (ddRADSeq). We hypothesized that inbreeding depression could result in positive correlations between genome-wide heterozygosity and performance traits (body mass and survival) and negative correlations between $F_{\text {grm }}$ and the same performance traits. Nevertheless, since those herds are still large (>8,000 individuals), we suspected that inbreeding depression could be low at this stage of demographic decline and have probably no lethal effects yet. Thus, higher correlations between genomic inbreeding indices and condition compared to survival were expected. Prior to analyses, we investigated the genetic differentiation between the two herds to confirm with SNP previous results obtained with microsatellites showing no differentiation between the herds (Boulet, Couturier, Côté, Otto, \& Bernatchez, 2007).

\section{2 | METHODS}

\subsection{Study area and data collection}

Using nets fired from helicopters, we captured and sampled 149 caribou of the RG herd ( 90 females; 59 males) between 2000 and 2014 and 251 caribou of the RAF herd (159 females; 92 males) between 1996 and 2016, following the guidelines from the Canadian Council on Animal Care. Individuals were captured up to five times over the study period, but most (85.5\%) were captured only once. We collected muscle biopsies ( $n=361)$, hairs $(n=27)$ or blood $(n=12)$ samples on each animal and froze all samples except for some biopsies $(n=150)$ that were stored in ethanol $(\geq 70 \%)$ at room temperature. We used EDTA to preserve blood samples and prevent them from coagulating. From the 400 individuals, 222 ( $\geq 2$ years old) were fitted with tracking collars using different satellite networks (Argos, Iridium, Globalstar), allowing the assessment of annual survival from capture date to 2017. Mortalities were signalled by collars after 12-24 hr of inactivity and were then confirmed on the field based on visual cues when retrieving the collars. In addition, 253 caribou ( $\geq 1$ year) were weighted to the nearest $0.1 \mathrm{~kg}$ using a hanging scale. Annual survival and body mass (collected in January, February, March, June, October or November) were considered as indices of individual performance (Taillon, Brodeur, Festa-Bianchet, \& Côté, 2011) and were included in our models as response variables. Moreover, 55 calves ( $<2$ days; Taillon, Barboza, \& Côté, 2013) captured between 2007 and 2009 were used to ensure our sample (that did not include calves) was representative of heterozygosity levels at birth by comparing heterozygosity between calves and yearlings $(n=49)$ born in those years. Some of those calves $(n=20)$ were paired on the field with females included in our data set.

\subsection{DNA extractions}

We used Qiagen DNeasy Blood and Tissue Kit (Qiagen, Inc.) to extract DNA. To digest hairs ( 100 hairs), we used 1.3 times the recommended volume of ATL lysis buffer and proteinase $\mathrm{K}$ and added $45 \mu \mathrm{l}$ of dithiothreitol (DTT; $100 \mathrm{mg} / \mathrm{ml}$ ). To maximize DNA yield, we eluted in $100 \mu$ l elution buffer for blood and hair samples and $200 \mu$ l otherwise; for all sample types, flow-through went through columns a second time at the final elution. We assessed DNA quality and checked for degradation on agarose gels. Most samples of blood or biopsies led to high-to-moderate DNA quality (low-to-medium 
degradation), whereas hair samples led to lower DNA quality with higher levels of degradation. We quantified DNA concentrations with a Qubit 2.0 Fluorometer (Life Technologies) and standardized all samples to $200 \mathrm{ng} / \mu$ l before library construction.

\section{3 | ddRADSeq library construction and sequencing}

We constructed ddRADSeq libraries from caribou's genomic DNA following the general protocol from Peterson, Weber, Kay, Fisher, and Hoekstra (2012) with some modifications. Following recommendations of Mastretta-Yanes et al. (2015), we replicated 70 (17.5\%) of our samples: 40 intra-library replicates and 30 inter-library replicates. We used a combination of 47 uniquely tagged $P 1$ adaptors and 10 PCR indices to construct 10 libraries containing 47 DNA samples each. For each sample, 200 ng of DNA was digested with 20 units each of Sbfl (CCTGCA/GG) and Mspl (CC/GG). After ligation of P1 and $\mathrm{P} 2$ adaptors to Sbfl and Mspl cutsite overhang, respectively, we pooled all samples from one library and purified it using Agencourt AMPure XP (Beckman Coulter) or NucleoMag (Macherey-Nagel) systems with a DNA:magnetic bead solution ratio $(\mathrm{v} / \mathrm{v})$ of $1: 1.8$. We then selected fragments between 200 and 500 bp on agarose gels (1.6\%), using Promega Wizard SV Gel and PCR Clean-Up System to perform gel extraction. Final amplification was achieved in 16 reactions of $20 \mu \mathrm{l}$ containing $12.6 \mu \mathrm{l}$ nanopure water, $4 \mu \mathrm{l}$ Phusion ( HF 5× Buffer (New England Biolabs), $0.4 \mu \mathrm{l}$ dNTPs (10 mM), $0.4 \mu \mathrm{l}$ each forward and reverse primers (10 $\mu \mathrm{M}$; PCR1 and indexed PCR2), $0.2 \mu \mathrm{l}$ Taq Phusion HF (2,000 U/ml) and $2 \mu \mathrm{l}$ DNA template. After an initial denaturation step of $30 \mathrm{~s}$ at $98^{\circ} \mathrm{C}, 15$ cycles of $10 \mathrm{~s}$ at $98^{\circ} \mathrm{C}$, $10 \mathrm{~s}$ at $65^{\circ} \mathrm{C}$ and $30 \mathrm{~s}$ at $72^{\circ} \mathrm{C}$ were performed and followed by a final extension of $10 \mathrm{~min}$ at $72^{\circ} \mathrm{C}$. All 16 PCRs from the same library were then pooled and purified using Promega Wizard SV Gel and PCR Clean-Up System. The 10 pooled libraries were each sequenced on two lanes of Illumina HiSeq 4000 (with HiSeq 3000/4000 SBS Kit) by Fasteris (Switzerland).

\section{4 ddRADSeq data processing}

We used Cutadapt (v. 1.8.1; Martin, 2011) to remove adapter sequences from sequence files and FastQC (v. 0.11.2; Andrews, 2010) to assess data quality and detect adaptor contamination. Then, we used Stacks (v. 1.44; Catchen, Amores, Hohenlohe, Cresko, \& Postlethwait, 2011; Catchen, Hohenlohe, Bassham, Amores, \& Cresko, 2013) to demultiplex data and build a de novo SNP catalog. We tested different sets of Stacks core parameters (ustack - $m$ (2-6), $-M(2-6)$ and -max_locus_stacks (2-6) and cstack $-n(0-5))$, by varying one parameter at a time whereas the others remained at their default values, as suggested by Mastretta-Yanes et al. (2015), and chose the values that minimized error rates between replicates ( $n=70$ pairs) and maximized the amount of data recovered. To do so, we combined files from the two sequencing runs to obtain a depth of coverage that would be similar to that observed in our final set, but

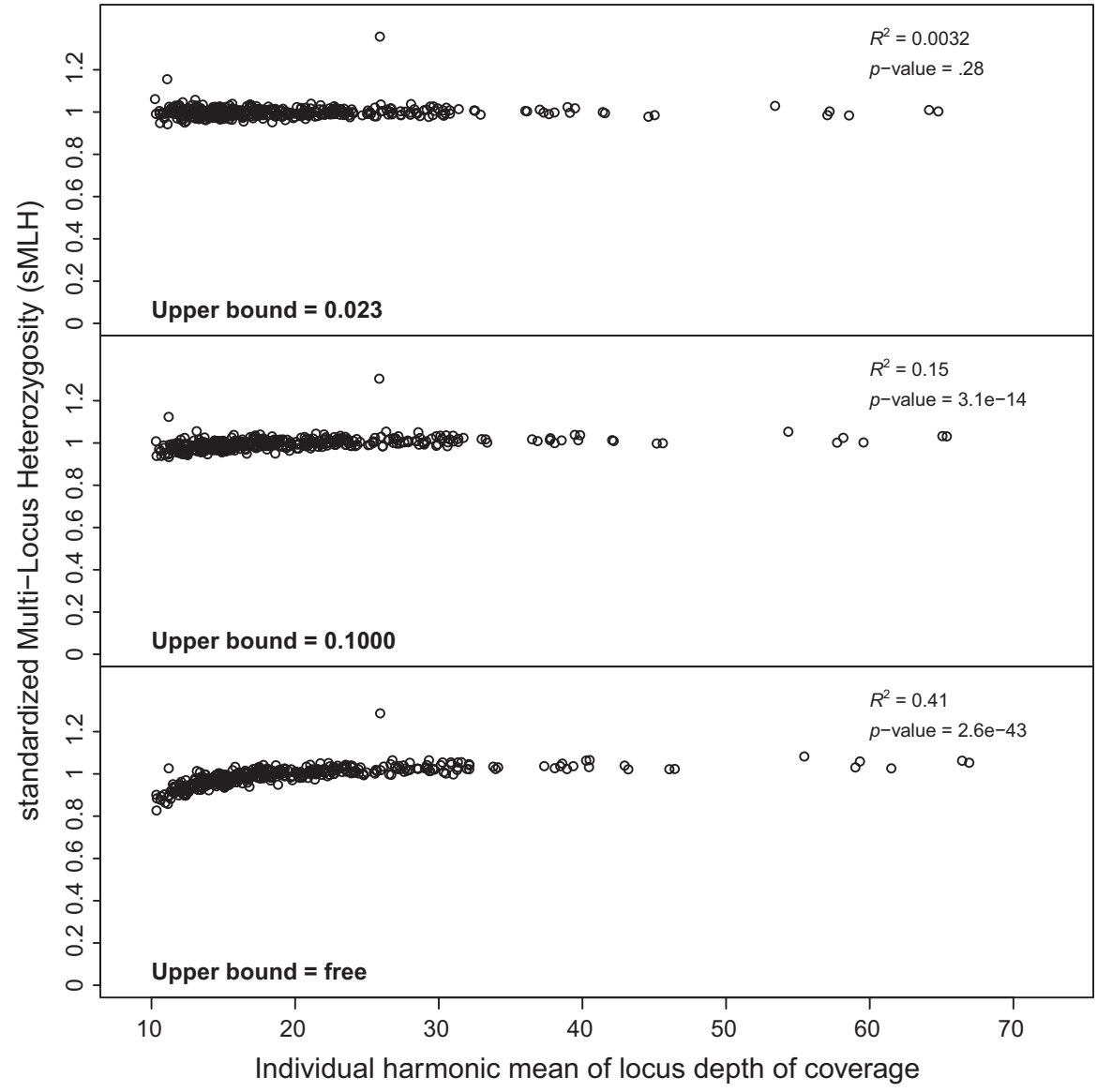

FIGURE 2 Correlations between standardized multi-locus heterozygosity (sMLH) and individual harmonic mean of locus depth of coverage in relation to different values of upper bound after filtration for -InI_lim $=-10$ in Rxstacks and without individuals that had more than $80 \%$ missing data. Stacks was run with optimal core parameter values identified by analysis of inter-replicates error rates

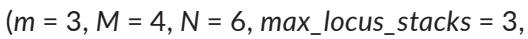
$n=3)$. Free upper bound means that the model SNP was used in Ustacks instead of the bounded model 
kept only the replicate pairs at this stage. First, using the default SNP calling model, we identified the optimal values of $-m(3),-M(4),-N$ (6), - -max_locus_stacks (3) and -n (3; error rates for each set of parameters are presented in Figures S1 and S2). Then, to compare upper bound values for the bounded model to the default (SNP) model, we used those optimal values in combination with each value of upper bound tested $(0.0125,0.023,0.5,0.1,0.15$ and 1 [default SNP model]). In preliminary analysis, we found that genomic inbreeding indices were strongly correlated, in a nonlinear way, with the individual harmonic mean of locus depth of coverage. This trend was consistent in both herds and sex. We found that filtering data with - Inl_lim $=-10$ (95\% of our loci had a log likelihood equal or higher than -10) in Rxstacks and eliminating individuals with more than $80 \%$ missing data made the relationship linear. We did so and then chose the value of upper bound that led to the weakest and least significant correlation between sMLH or $F_{\text {grm }}$ (see 'Assessment of genomic inbreeding indices' for details) and individual harmonic mean of locus depth of coverage (Figures 2 and S3). The upper bound values of 0.0125 or 0.023 for the bounded model both led to very weak correlations that were nonsignificant for $\mathrm{SMLH}$ and barely significant for $F_{\text {grm }}$, and we decided to use 0.023 as it also corresponded to the highest PhiX error rate reported for our sequencing runs. Note that error rates between replicates did not strongly vary when the upper bound value changed (result not shown). In all Stacks runs, including the one performed to produce our final set, we specified in the Populations component only one population, as RG and RAF herds were shown to be genetically undifferentiated (Boulet et al., 2007; result confirmed in the present study) and set $-m$ (minimum stack depth required to call a genotype in an individual) to $8,-r$ (minimum percentage of individuals required to process a locus) to 0.5 and min_maf (minimum minor allele frequency required to process a nucleotide site at a locus) to 0.01 . The $-m$ value seemed to offer the best trade-off between the number of retained loci and genotype

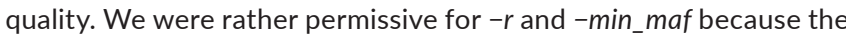
heterozygosity scores were standardized to account for missing data and mean observed heterozygosity at genotyped loci. This allowed retaining a maximum number of loci for subsequent analysis. To produce the final data set, we combined all replicate files in order to increase depth of coverage and genotype accuracy and ran Stacks with all parameters set to their optimal values identified above.

\section{5 | Populations structure}

To assess the genetic differentiation between the two herds, we filtered the data set described in 'ddRADSeq data processing' by keeping only a SNP by locus and using $r=.8$ in Populations to avoid artificially increasing or decreasing differentiation between populations. This subset included 6,384 SNPs typed for 362 individuals (10.44\% missing data). Prior to analysis, input files were exported in the appropriate format using radiator (v. 0.0.5; Gosselin, 2017). We removed from the data set known related individuals (e.g. mothercalf pairs identified in the field) or related individuals detected with a genetic relatedness matrix obtained using the 'snpgdsGRM' function implemented in the R SNPRelate package (Zheng et al., 2012). This resulted in a data set including 344 individuals. Genetic differentiation between herds was then investigated, using classical F-statistics according to Weir and Cockerham (1984) implemented in StAMPP (Pembleton, Cogan, \& Forster, 2013), principal component analysis (PCA) and discriminant analysis of principal components (DAPC; Jombart, Devillard, \& Balloux, 2010) implemented in adegenet (Jombart, 2008). DAPC was run on a priori defined clusters, that is, RG and RAF herd membership. We performed a cross-validation analysis to identify the optimal number of principal components (PCs) to retain in the DAPC analyses. To do so, we carried out a stratified cross-validation of DAPC using the function xvalDapc in adegenet, with 100 replicates at each level of PC retention and the data divided into two sets, that is, a training set (90\% of the data) and a validation set ( $10 \%$ of the data). Afterwards, the optimal number of PCs was used in subsequent analysis.

\subsection{Assessment of genomic inbreeding indices}

We computed individual SMLH with the function 'sMLH' implemented in the package inbreedR (Stoffel et al., 2016) in $R$ (v. 3.4.0; $R$ Core Team, 2017). sMLH accounts for differences in the identity of the loci genotyped in all individuals and corrects the heterozygosity score for the mean heterozygosity observed at the typed loci in the rest of the population. Here, sMLH was computed for individuals from the two herds simultaneously. Then, using the ' $r 2$ _hf' function of the InbreedR package (Stoffel et al., 2016), we computed the expected correlation between sMLH and inbreeding $(F)$ with 100 bootstraps. We computed $F_{\text {grm }}\left(F^{\prime \prime \prime}\right)$ in GCTA (Yang et al., 2011), using the command '-ibc'. In addition, to ensure the reliability of our data sets to properly detect HFCs, we assessed identity disequilibrium (covariance of heterozygosity among loci of a given individual; Weir \& Cockerham, 1973; Szulkin et al., 2010) by computing the heterozygosity-heterozygosity correlation (HHC; Balloux et al., 2004) and the $g_{2}$ value (David, Pujol, Viard, Castellas, \& Goudet, 2007; Szulkin et al., 2010). HHC is a measure of correlation of heterozygosity across loci. The stronger the correlation is, the more the multi-locus heterozygosity is representative of global genetic diversity (Balloux et al., 2004). The $g_{2}$ value measures the variance in the degree of covariance of heterozygosity at the individual level. The higher the variance is, the more likely it is to detect an HFC resulting from general effects in the sample if there is actually one in the population (David et al., 2007; Szulkin et al., 2010). HHC values were assessed using 100 iterations, and the $g_{2}$ values were obtained using 100 permutations and 10 bootstraps, with the functions ' $\mathrm{HHC}$ ' and 'g2_snps' of the InbreedR package (Stoffel et al., 2016). Because the data sets used to assess the effect of sMLH on body mass and annual survival did not include the same individuals, $\mathrm{HHC}$ and $g_{2}$ were computed separately for both data sets. Although $\mathrm{HHC}$ and $g_{2}$ are useful tools to detect identity disequilibrium, it was shown that HFCs could still occur and be caused by inbreeding depression in populations in which identity disequilibrium could not be detected (Kardos, Allendorf, \& Luikart, 2014; Miller \& Coltman, 2014). 


\section{7 | Variation of genomic inbreeding indices through time and age}

We suspected that the abrupt decline observed in the two herds could have caused a reduction of sMLH and an increase of $F_{\text {grm }}$ in more recent cohorts. We thus tested for variation of those genomic inbreeding indices through time by fitting linear models with either sMLH or $F_{\text {grm }}$ as response variables and cohort (birth year; coded as a continuous variable), herd and the interaction between the two as predictor variables. We used the argument weights to account for different sample sizes in each cohort of each herd. Furthermore, the sample used for HFC analyses, including only individuals captured at ages $>1$ year, may not have been representative of individuals born during our sampling period if inbred individuals died early in life before we could sample them. We thus compared the sMLH scores and $F_{\text {grm }}$ values of calves ( 0 years) born between 2007 and 2009 to that of individuals born in the same period, but captured for the first time as yearlings. To do so, we fitted independent linear models with each of the two genomic inbreeding indices ( $\mathrm{sMLH}$ and $F_{\text {grm }}$ ) as response variables and with age, herd and year, all coded as categorical variables, as fixed effect with the R function 'Im' (R Core Team, 2017).

\section{8 | Relationships between genomic inbreeding indices and performance}

We used linear mixed-effects models with the function 'Imer' implemented in the $R$ package Ime4 (Bates, Mächler, Bolker, \& Walker, 2015) to assess the relationship between genomic inbreeding indices and body mass. Body mass was log-transformed to improve homogeneity of variances, and $\mathrm{sMLH}$ and $F_{\text {grm }}$ were centred to improve convergence of models. To investigate the possible effect of genomic inbreeding indices in interaction with sex, age or herd, we adopted a model selection approach. We first considered a baseline model that included age, Vage, sex, herd and month of capture as fixed-effect variables, as these factors are known to influence caribou body mass (Couturier, Côté, Huot, \& Otto, 2009a; Couturier et al., 2009b; Parker, 1981). We added year and individual identity as random factors to consider annual variation and repeated measures on individuals. To the baseline model, we added $\mathrm{sMLH}$ and $\mathrm{sMLH}^{2}$ or $\mathrm{F}_{\mathrm{grm}}$ and $\mathrm{F}_{\mathrm{grm}}^{2}$ as fixed-effect variables to build simple models that included genomic inbreeding indices. Considering a potential quadratic effect of the genomic inbreeding indices on performance, we accounted for a potential threshold under which a decrease in inbreeding would not have any effect on performance traits. Then, we derived competitive models including interactions between the simple (sMLH or $F_{\text {grm }}$ ) and quadratic $\left(\mathrm{sMLH}^{2}\right.$ or $\mathrm{F}_{\mathrm{grm}}^{2}$ ) terms of genomic inbreeding indices and sex, herd, age and Vage. All models were compared using Akaike's information criterion for small sample sizes (AICC), and we selected the model with the lowest value of AICc. $\triangle \mathrm{AICC}$ and AICc weights $\left(\omega_{\mathrm{i}}\right)$ were computed with the $R$ package AICcmodavg (Mazerolle, 2017). We used the same approach to test for the effect of genomic inbreeding indices on annual survival in adults ( $>2$ years). Annual survival was coded as a binary variable with a value of 1 if the individual was alive during a given year and 0 if the individual was dead. Malfunctioning collars were censored starting from the point of malfunction. We fitted generalized mixed-effects models with a binomial distributed error (logit link function), using the 'glmer' function implemented in the package Ime4 (Bates et al., 2015). The baseline model included age, age ${ }^{2}$, herd and sex (Couturier, Otto, Côté, Luther, \& Mahoney, 2010; Loison, Festa-Bianchet, Gaillard, Jorgenson, \& Jullien, 1999) as fixed-effect variables and year and individual identity as random factors. In the derived models, we added the simple (sMLH or $F_{\text {grm }}$ ) and quadratic $\left(\mathrm{s} \mathrm{MLH}^{2}\right.$ or $\mathrm{F}_{\mathrm{grm}}^{2}$ ) terms of the genomic inbreeding indices and their interaction with sex, herd, age and age ${ }^{2}$.

\section{3 | RESULTS}

\section{1 | Population structure}

We observed a significant but very low genetic differentiation between the RG and RAF herds ( $F_{\mathrm{ST}}: 0.0027,95 \% \mathrm{Cl}$ : [0.0024, 0.0029], $p$-value $<.001)$. In line with this estimation, two genetic clusters appeared clearly on PCA (Figure 3a). Cross-validation determined that the use of the first 10 PCs for the DAPC was optimal. Although the 10 PCs portrayed only $12 \%$ of the variance, it gave the highest predictive success $(88.9 \%)$ and the lowest root mean squared error (11.9\%). Overall, DAPC indicated some genetic overlap between the two clusters, but $82.6 \%$ caribou of the RG herd and $92.1 \%$ caribou of the RAF herd were assigned to the correct herd (Figure 3b,c). In addition, the two multivariate analyses revealed admixture between the two herds as well as individual herd switching (Figure 3). The genetic relatedness matrix did not reveal strong particular individual clustering (results not shown), but confirmed that relatedness between known related individuals (i.e. mother-calf pairs of both herds; RG = 11 pairs and RAF $=5$ ) was as expected $\sim 0.5$ $(0.45 \pm 0.04[S D])$.

\subsection{Assessment of genomic inbreeding indices}

Before the final SNP calling procedure, thirty-six of 400 individuals were excluded from the analyses because they presented more than $80 \%$ missing data. At the end of our de novo SNP calling procedure, we obtained 22,073 SNPs distributed at 14,847 loci. We then eliminated two individuals who had very high multilocus heterozygosity scores before we computed SMLH as we suspected that they were contaminated during DNA extraction or library preparation. The median of individual locus depth of coverage was 22.08 reads/nonmissing locus. Individuals scored between 4,408 and 21,713 SNPs with a mean of 16,983 \pm 4,198 (SD). sMLH scores varied between 0.94 and 1.06 and were moderately correlated with (unstandardized) multi-locus heterozygosity (Pearson's $r=.40$ for RG and .44 for RAF) and with $F_{\text {grm }}$ (Pearson's $r=-.41$ for RG and -.40 for RAF; Figure 4). As predicted, given the large number of loci used here (i.e. >20k SNPs), the expected correlation between sMLH and $\mathrm{F}$ was $1(95 \% \mathrm{Cl}$ : 
(a)

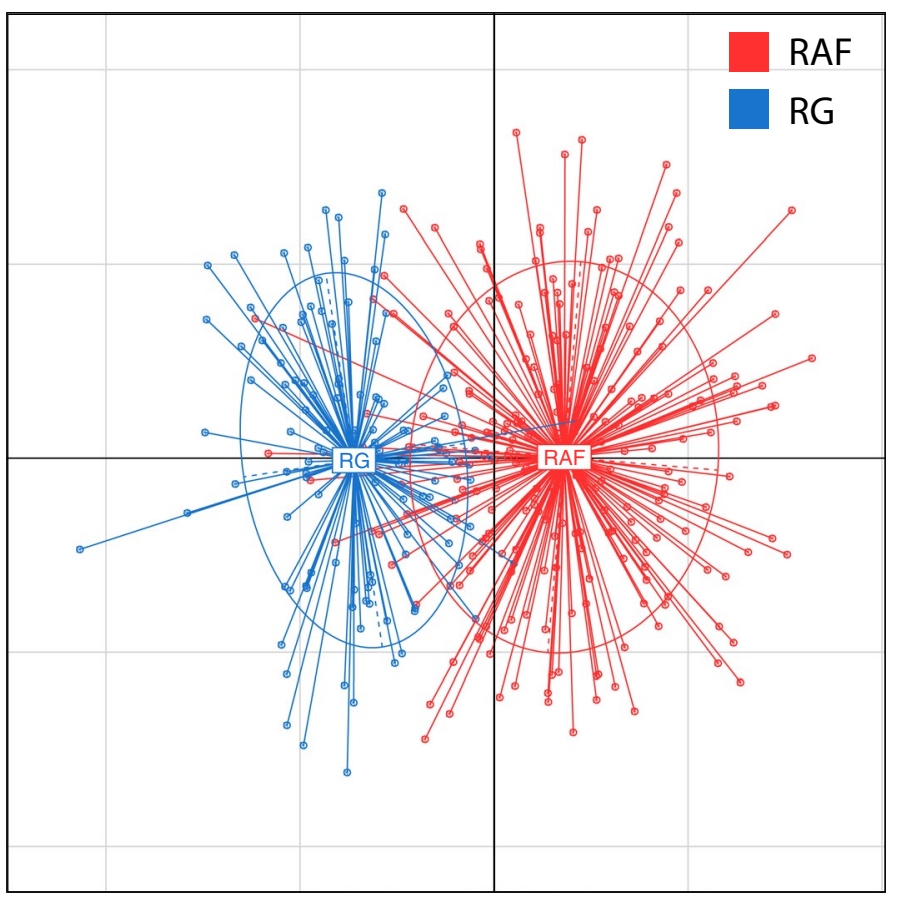

(b)

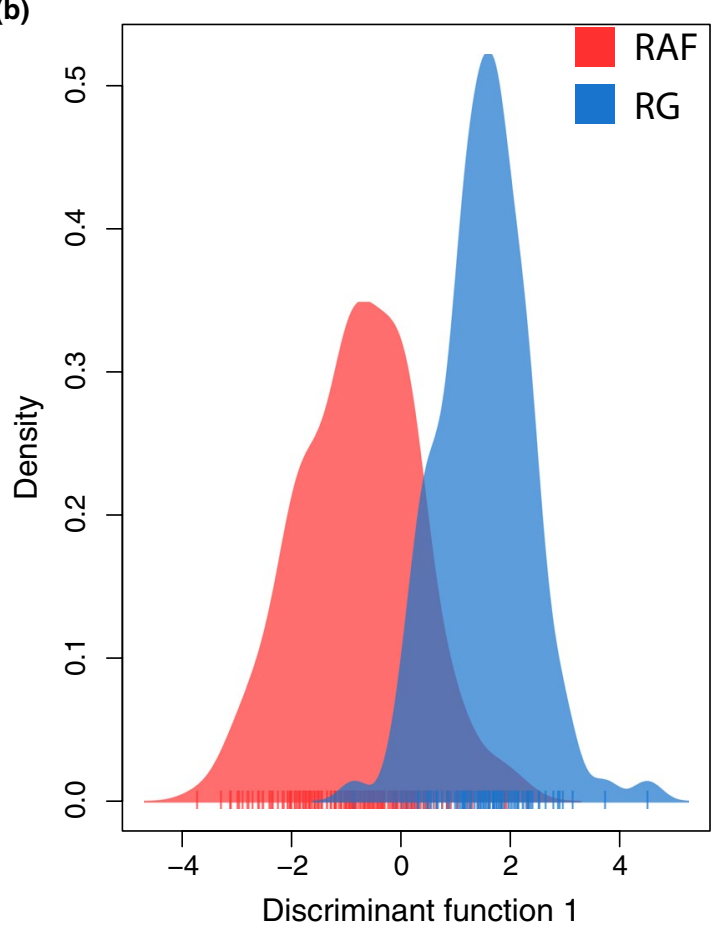

RG
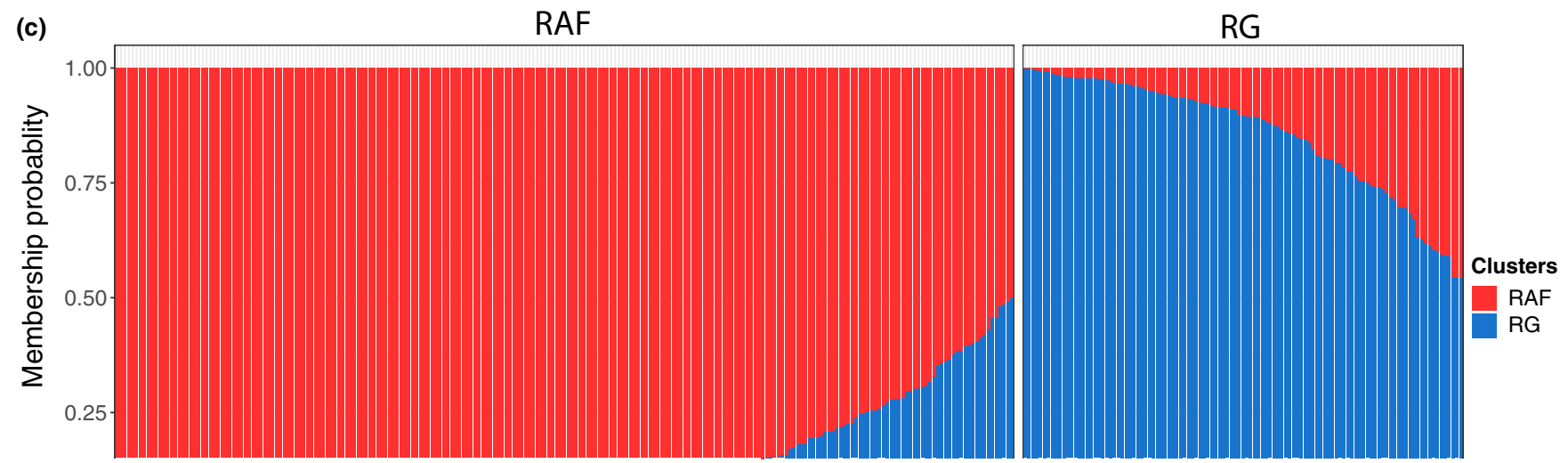

FIG URE 3 (a) Principal component analysis (PCA) scatter plot ( $x$-axis: 2.99\%; $y$-axis: 2.15\%). Dots represent individuals, with colours denoting sampling origin and inclusion of $95 \%$ inertia ellipses. (b) Individual density plot on the first discriminant function of the discriminant analysis of principal components (DAPC); and (c) group assignment probability of individuals to the two clusters according to DAPC, drawn across 362 migratory caribou individuals. Cluster \#1 corresponds mainly to individuals from the Rivière-aux-Feuilles herd (RAF; in red), and Cluster \#2 corresponds to individuals from the Rivière-George herd (RG; in blue)

[1, 1]; Figure S4), confirming the power of our marker sets to detect HFCs. $F_{\text {grm }}$ ranged between -0.16 and 0.05 . We did not detect differences of sMLH between herds (RAF herd mean \pm SE: $1.001 \pm 0.001$ and $R G$ herd mean $\pm S E$ : $0.999 \pm 0.002$; two-sample $t$ test $t=1.170, d f=432, p$-value $=.24)$, nor significant differences of $F_{\text {grm }}$ (RAF herd mean \pm SE: $-0.026 \pm 0.001$ and RG herd mean $\pm S E$ : $-0.025 \pm 0.002$; Wilcoxon rank-sum test $W=21,015$, $p$-value $=.58$ ). The average (unstandardized) observed heterozygosity was $0.23 \pm 0.01(S D)$ in both herds and ranged between 0.20 and 0.27 . The $\mathrm{HHC}$ values were $0.30 \pm 0.05(S D)$ for the mass data set and $0.33 \pm 0.05(S D)$ for the survival data set. The $g_{2}$ values were $3.8 \times 10^{-4} \pm 4.4 \times 10^{-4}\left(\mathrm{SE} ; p\left(g_{2}>0\right)=1\right)$ for the mass data set and $1.2 \times 10^{-4} \pm 3.8 \times 10^{-4}\left(\mathrm{SE} ; p\left(g_{2}>0\right)=1\right)$ for the survival data set.

\subsection{Variation of genomic inbreeding indices through time and age}

$\mathrm{sMLH}$ and $F_{\text {grm }}$ did not vary significantly through the sampling period (Figures S5 and S6) or between herds (Tables S1 and S2). We found no significant difference in SMLH or $F_{\text {grm }}$ between individuals born between 2007 and 2009 and captured for the first time either as calves or as yearlings (Tables S3 and S4).

\section{4 | Relationships between genomic inbreeding indices and performance}

Model selection performed with sMLH and $F_{\text {grm }}$ produced similar results. In the models, $F_{\text {grm }}$ had estimates of the opposite sign 
RAF

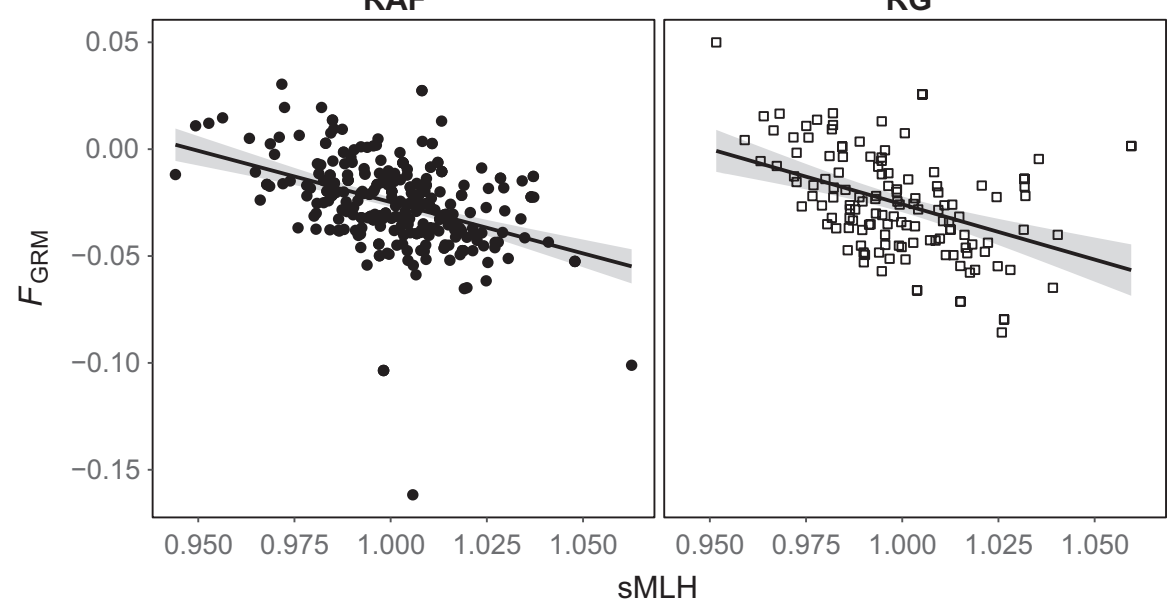

FIGURE 4 Correlation between standardized multi-locus heterozygosity (sMLH) and genomic inbreeding $\left(F_{\text {grm }}\right)$ for 434 genotyped caribou from Rivière-aux-Feuilles herd (RAF; $n=297$, $y=-0.48 x+0.45$, Pearson's $r=-.40$ ) and Rivière-George herd (RG; $n=137$; $y=-0.52 x+0.49$, Pearson's $r=-.41$ ), respectively

\begin{tabular}{lrrrrrr} 
& & & & \multicolumn{2}{c}{$95 \%$ Confidence interval } \\
\cline { 6 - 7 } Variable & Estimate & \multicolumn{1}{c}{ SE } & t-value & Lower bound & Upper bound \\
\hline Intercept & 2.91 & 0.08 & 37.4 & 2.76 & 3.06 \\
\hline Age & -0.24 & 0.02 & -14.4 & -0.27 & -0.20 \\
\hline VAge & 1.25 & 0.07 & 18.6 & 1.12 & 1.38 \\
\hline Herd-Rivière-George & 0.10 & 0.02 & 5.7 & 0.07 & 0.14 \\
\hline Sex-male & 0.15 & 0.03 & 5.9 & 0.10 & 0.20 \\
\hline Month of capture-February & -0.09 & 0.04 & -2.1 & -0.17 & -0.01 \\
\hline Month of capture-March & 0.01 & 0.04 & 0.3 & -0.06 & 0.08 \\
\hline Month of capture-June & -0.23 & 0.04 & -5.3 & -0.31 & -0.14 \\
\hline Month of capture-October & -0.01 & 0.04 & -0.3 & -0.10 & 0.07 \\
\hline Month of & 0.06 & 0.05 & 1.2 & -0.04 & 0.16 \\
\hline capture-November & & & & & \\
\hline
\end{tabular}

TABLE 1 Estimates of the body mass baseline model for migratory caribou from the Ungava Peninsula

Lower bounds and upper bounds of the $95 \%$ confidence intervals on estimates are provided in addition to the standard errors (SE) and $t$-values. Variables with $95 \% \mathrm{Cl}$ that do not overlap 0 are considered to have a significant effect and are in bold. Levels of reference are Female for sex, Rivière-aux-Feuilles for herd and January for month of capture. Baseline model: $\log ($ mass $) \sim$ age $+\sqrt{ }$ a ge + sex + herd + month of capture $+(1 \mid$ year $)+(1 \mid$ individual identity $)$.

compared to SMLH, as the two variables are negatively correlated, but significance was similar. Only results for SMLH candidate sets and models are presented here, and results for $F_{\text {grm }}$ are detailed in Electronic Supplementary Material (Tables S5 and S6). Regarding sMLH model selection, the baseline model for the body mass candidate set was the best model $\left(\triangle \mathrm{AICc}=0\right.$ and $\omega_{i}=0.49$; $\triangle \mathrm{AIC}$ of the second-ranked model $=3.1$; Table S7). Age, Vage, herd, sex and some months of capture had a significant effect on body mass in the baseline model (Table 1). Body mass increased from 1 to 2 years and plateaued after that age at around $90 \mathrm{~kg}$ for females and $106 \mathrm{~kg}$ for males. Individuals from the RG herd were on average $8.07 \mathrm{~kg}$ heavier than their RAF counterparts in June, and all individuals were on average heavier in fall and lighter at the beginning of summer, compared to winter months. Next candidate models did not include significant effects of SMLH or $\mathrm{sMLH}^{2}$ and their interactions (Figure S7), nor of $F_{\mathrm{grm}}$ or $\mathrm{F}_{\mathrm{grm}}^{2}$ and their interactions.
The baseline model was also selected as the best model for survival $\left(\triangle \mathrm{AICc}=0\right.$ and $\omega_{i}=0.55 ; \Delta \mathrm{AICc}$ of the second-ranked model = 3.3; Table S8). However, only herd had a significant effect on survival (Table 2), which was lower for individuals from the RG herd in comparison with RAF herd (Odds ratio $=0.46,95 \% \mathrm{Cl}$ : $[0.27$, 0.78]; Figure 5). None of the next-ranked models included significant effect of sMLH or its interactions.

\section{4 | DISCUSSION}

\section{1 | Population structure}

Contrarily to what has been shown previously (Boulet et al., 2007; Yannic et al., 2016), we found a significant but very low differentiation between RG and RAF herds. The large number of SNPs used in our study improved population structure delineation in this context of weak genetic structure (see also Benestan et al., 
TAB LE 2 Estimates of the survival baseline model for migratory caribou from the Ungava Peninsula

\begin{tabular}{|c|c|c|c|c|c|c|}
\hline \multirow[b]{2}{*}{ Variable } & \multirow[b]{2}{*}{ Estimate } & \multirow[b]{2}{*}{ SE } & \multirow[b]{2}{*}{ Z-value } & \multirow[b]{2}{*}{$p$-value } & \multicolumn{2}{|c|}{$95 \%$ Confidence interval } \\
\hline & & & & & Lower bound & Upper bound \\
\hline Intercept & 2.44 & 0.33 & 7.5 & .00 & 1.80 & 3.07 \\
\hline Centred age & -0.25 & 0.16 & -1.6 & .10 & -0.56 & 0.05 \\
\hline$(\text { Centred age })^{2}$ & -0.07 & 0.07 & -0.9 & .36 & -0.21 & 0.08 \\
\hline Sex-male & -0.17 & 0.26 & -0.7 & .51 & -0.69 & 0.34 \\
\hline Herd-Rivière-George & -0.77 & 0.27 & -2.8 & .01 & -1.30 & -0.24 \\
\hline
\end{tabular}

Lower bounds and upper bounds of the $95 \%$ confidence intervals on estimates are provided in addition to the standard errors (SE), Z-values and $p$ values. Variables with $95 \% \mathrm{Cl}$ that do not overlap 0 are considered to have a significant effect and are in bold. Levels of reference are Female for sex and Rivière-aux-Feuilles for herd. Baseline model: annual survival age $+\mathrm{age}^{2}+\mathrm{sex}+$ herd + (1|year) + (1|individual identity).

2015) and likely improved the detection of differences compared to microsatellite markers (Fischer et al., 2017; Gärke et al., 2011; Liu, Chen, Wang, Oh, \& Zhao, 2005). In addition, it appears that the recent demographic decline of both populations has been accompanied by a reduction in their overlapping ranges (Le Corre, 2016; Figure 1) that could have contributed to reduce gene flow. Nevertheless, the overall very low level of differentiation we observed and the few cases of herd switching observed in our data set are concordant with previous observations of high gene flow between RG and RAF herds (Boulet et al., 2007; Yannic et al., 2016).

\section{2 | Assessment of genomic inbreeding indices}

It was suggested that SNP markers would greatly improve HFC studies by increasing representativeness of genome-wide diversity

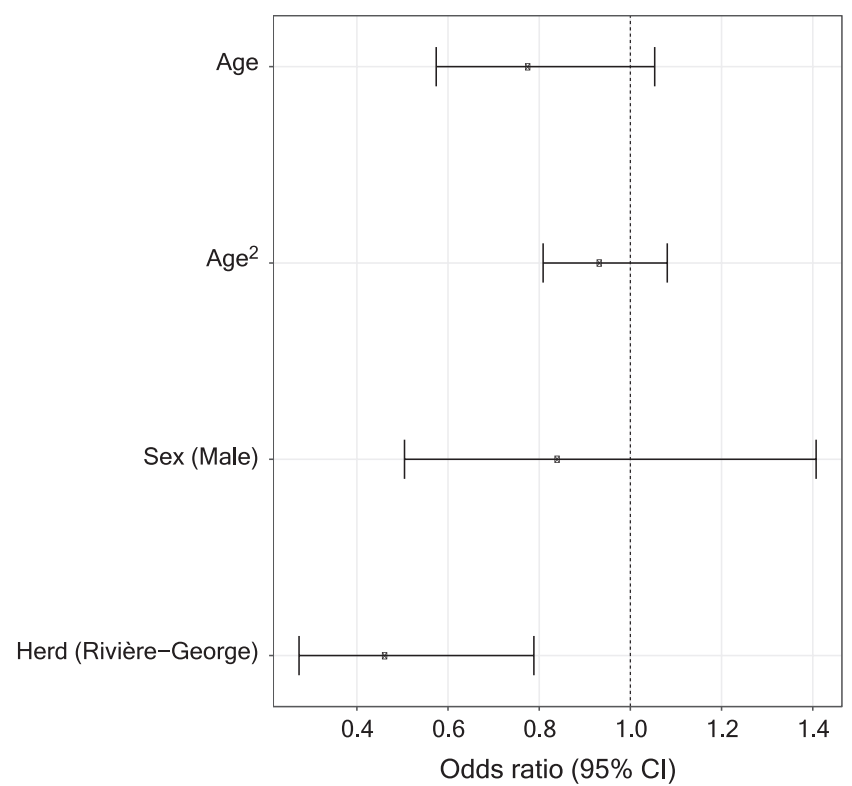

FIGURE 5 Odds ratios and 95\% confidence interval (Cl) for the fixed-effect variables included in the baseline model of survival. Odds ratios with $\mathrm{Cl}$ that do not overlap 1 are considered statistically significant. Levels of reference are Female for sex and Rivière-aux-Feuilles for herd. Baseline model: annual survival $\sim$ age + age $^{2}+$ sex + herd $+(1 \mid$ year $)+(1 \mid$ individual identity $)$
(Kardos et al., 2016; Miller et al., 2014). Accordingly, it was shown in harbour seal (Phoca vitulina) that the strength of an HFC detected in a natural population increased significantly when heterozygosity was estimated with 14,585 SNP markers rather than 27 microsatellites (Hoffman et al., 2014). Although we found higher values of HHC in our data sets than those usually reported in HFC studies using microsatellites (Guinand et al., 2013; Queirós, Vicente, Alves, de la Fuente, \& Gortazar, 2016; Voegeli, Saladin, Wegmann, \& Richner, 2013), our values were somewhat small, indicating that our estimate of heterozygosity may not have been representative of inbreeding levels (Balloux et al., 2004). In preliminary analyses, we found that some of the filters we applied in Stacks to reconstruct SNPs helped reduce the unintended correlation between genomic inbreeding indices and depth of coverage, but also reduced dramatically the values of HHC. HHC values should be high if markers' heterozygosity was highly dependent on a third variable, like the depth of coverage. Thus, it was not surprising that $\mathrm{HHC}$ values drastically decreased as the relationship between sMLH and depth of coverage weakened. The effect of the number of markers used to assess heterozygosity (Miller \& Coltman, 2014) or marker type and population history (Miller et al., 2014) on identity disequilibrium has been studied previously, but the effect of depth of coverage has not. Here, we used error rates between replicate samples (Mastretta-Yanes et al., 2015) to calibrate filtering parameters in Stacks, but those were not accurate indicators of the correlation between depth of coverage and genomic inbreeding indices. Further studies should explore the impact of bioinformatic filters on SNP-based estimates of multi-locus heterozygosity, $F_{\text {grm }}$ and identity disequilibrium and, in the context of HFC studies, determine the best approach to adopt for data filtering. Meanwhile, SNPs could still improve HFC studies because they provide a broader representation of general genetic diversity than microsatellites by covering coding and noncoding regions of the genome (Balloux et al., 2004; Miller \& Coltman, 2014; Miller et al., 2014).

\section{3 | Relationships between genomic inbreeding indices and performance}

We used HFCs to detect inbreeding depression in RG and RAF declining herds of migratory caribou. We studied the association of 
genome-wide, multi-locus heterozygosity and $F_{\text {grm }}$, an inbreeding coefficient based on genomic relatedness, inferred with 22,730 SNPs with two performance traits: body mass and annual survival. The effects of nongenetic variables on body mass and survival conform to what had been found previously (Couturier et al., 2009a,b; Parker, 1981), and we did not find any effect of heterozygosity, nor inbreeding coefficient, on these traits. On the contrary, positive effects of heterozygosity on reproductive success and survival have been found in a population of European shag (Phalacrocorax aristotelis) that presented similar levels of demographic decline as the RAF herd (Velando et al., 2015), but also high philopatry and a much smaller population size (a few hundreds). Those factors have probably increased the probability of inbreeding in this population (Velando et al., 2015). In our study, genomic inbreeding indices remained stable overtime. It is likely that the genetic diversity of the herds was shaped by the low population sizes preceding their augmentation in the 1970s and 1980s. Thus, it is expected that the return to similar sizes would not lead to decrease in population genetic diversity (e.g. in terms of number of alleles). Regarding individual genetic diversity, it was suggested that relaxed polygyny in caribou could attenuate the negative effect of population decline on genetic diversity as it increases the number of breeders in the population (Lovatt \& Hoelzel, 2014). The relatively large population sizes (a few to many thousands of individuals) also contribute largely to reduce inbreeding risk.

We are confident that our marker set reflected reliable biological information, as we found estimations of relatedness between known related individuals (i.e. mother-calf pairs of both herds) were as expected $\sim 0.5$. Nevertheless, the $g_{2}$ values were not significantly different from 0 , suggesting that the variance in inbreeding in our sample was too small to detect an HFC. This result could indicate that our sample did not capture all the variance observed in the herds, but we made our sample as representative as it could, a priori, by sampling 400 individuals of both sexes and various ages from the two herds, from different cohorts and in different seasons of a 20year period. In addition, we checked that our sample was representative of the populations before potential selection against inbred individuals could occur and eliminate variance in heterozygosity. We found no significant difference in sMLH scores or inbreeding coefficient between calves and yearlings born the same years, suggesting that our sample was representative of the population, even though we did not include calves in our models to assess the effect of genomic inbreeding indices. Thus, we believe that the low variance in inbreeding in our sample reflected the true levels of variance in the populations. In this study, the average (unstandardized) observed heterozygosity was $0.23 \pm 0.01$ (SD) for the RG herd and $0.23 \pm 0.01$ (SD) for the RAF herd. In another study conducted on those populations, observed heterozygosity estimated at 7 microsatellite markers was 0.71 for the RG herd $(n=98)$ and 0.73 for the RAF herd $(n=114$, Boulet et al., 2007). Similar results were more recently obtained with a larger panel of 16 microsatellite markers: 0.76 for the RG herd ( $n=71$ ) and 0.75 for the RAF herd ( $n=77 ;$ G. Yannic, unpublished). Since microsatellites are usually much more polymorphic than SNPs, because of their high mutation rate, their high number of alleles and the large ascertainment bias in polymorphic rates (Queiros et al., 2014), it was expected to observe lower heterozygosity estimates with SNPs (Kaiser et al., 2017). Here, the values of heterozygosity for the two types of markers are comparable to estimates of heterozygosity made in a population of bighorn sheep (Ovis canadensis; $n=26$ ) after a successful genetic rescue, where observed heterozygosity was 0.28 when estimated with 412 SNP markers and 0.64 when estimated with 200 microsatellite markers (Hogg, Forbes, Steele, \& Luikart, 2006; Miller et al., 2014). Thus, assuming that our sample was representative of studied populations, our results suggest that RG and RAF herds do not suffer from inbreeding. Unless there were substructure and nonrandom mating within RG and RAF herds, which is not supported by our data, or high genetic loads, which we did not address here, it is expected that relatively large populations with a few to many thousand individuals would not suffer from inbreeding, nor from inbreeding depression.

\section{5 | CONCLUSION}

In this study, we tested for the relationship between sMLH or $F_{\text {grm }}$, both proxies of inbreeding, and body mass and survival in caribou. Using a large number of markers ( 22k SNPs), we did not detect an association of the genomic inbreeding indices with body mass or annual survival. Furthermore, sMLH and $F_{\text {grm }}$ remained stable over the period monitored, which suggests that the rapid and intense demographic decline of the herds did not cause inbreeding depression in those populations. Additionally, we found a strong bias in individual heterozygosity associated with depth of sequencing coverage, which, once corrected for, reduced identity disequilibrium in our data set and may have reduced our ability to detect HFCs. This result highlights that depth of coverage should be taken into consideration when assessing heterozygosity and that, more generally, some questions remain regarding suitable filtration of SNP data, especially in HFC studies.

Although we found no evidence for HFCs, the strong rate of decline observed in RG and RAF herds could have and could continue to increase levels of genetic drift and lead to the loss of adaptive genetic variation (Allendorf, 1986; Taylor, Jenkins, \& Arcese, 2012) or to the accumulation of deleterious mutations (Lohr \& Haag, 2015; Perrier, Ferchaud, Sirois, Thibault, \& Bernatchez, 2017) at the population level. Further studies should focus on direct HFCs in those populations to understand how such processes could impair individual performance and limit evolutionary potential, especially in the face of climate change, where genetic diversity would provide a selective advantage (Allendorf et al., 2013; Forcada \& Hoffman, 2014).

\section{ACKNOWLEDGMENTS}

We thank C. Miquel, D. Rioux, L. Denoyelle, T. Capblanc, N. CurtGrand-Gaudin and N. Tissot as well as the AnaBM (USMB) and AEEM (UGA) laboratory facilities for their help and support during 
the laboratory work. We acknowledge C. Landry, J. Turgeon, T. Bilde, deciding editor, and two anonymous reviewers for their comments that helped improve the quality of this manuscript and $M$. LeCorre for his help with Figure 1. We are indebted to the ministère des Forêts, de la Faune et des Parcs (MFFP) of Québec for capture and monitoring of caribou, especially S. Rivard, V. Brodeur and J. Taillon. We are grateful for the logistic and financial resources made available by Caribou Ungava and the MFFP. The funding of Caribou Ungava is provided by the Natural Sciences and Engineering Research Council of Canada, the MFFP, ArcticNet, the Department of Environment and Conservation of Newfoundland and Labrador, Tata Steel Minerals Canada Limited, Hydro-Québec, GlenCore-Mine Raglan, Grand Council of the Crees, Torngat Wildlife, Plants and Fisheries Secretariat, Société Makivik-Air Inuit, Exploration Osisko Baie-James, Azimut Exploration and Fédération des Pourvoiries du Québec. Funding for laboratory work was also provided by a LabEx OSUG@2020 grant. M. Gagnon was supported by the Natural Sciences and Engineering Research Council of Canada, the Fonds de Recherche Nature et Technologies du Québec and Caribou Ungava.

\section{DATA AVAILABILITY}

Genetic data and some ecological data are available at https://doi. org/10.5061/dryad.crjdfn30k. Additional data could be made available on demand.

\section{ORCID}

Marianne Gagnon (iD https://orcid.org/0000-0001-8125-312X

Glenn Yannic (iD https://orcid.org/0000-0002-6477-2312

Steeve D. Côté iD https://orcid.org/0000-0002-4875-1917

\section{REFERENCES}

Allendorf, F. W. (1986). Genetic drift and the loss of alleles versus heterozygosity. Zoo Biology, 5, 181-190. https://doi.org/10.1002/ (ISSN)1098-2361

Allendorf, F. W., Aitken, S. N., \& Luikart, G. (2013). Conservation and the genetics of populations, 2nd ed. Oxford, UK: Willey-Blackwell.

Andrews, S. (2010). FastQC: A quality control tool for high throughput sequence data. Available online at: https://www.bioinformatics.babra ham.ac.uk/projects/fastqc

Balloux, F., Amos, W., \& Coulson, T. (2004). Does heterozygosity estimate inbreeding in real populations? Molecular Ecology, 13, 30213031. https://doi.org/10.1111/j.1365-294X.2004.02318.x

Bates, D., Mächler, M., Bolker, B. M., \& Walker, S. C. (2015). Fitting linear mixed-effects models using Ime4. Journal of Statistical Software, 67, 1-48.

Benestan, L., Gosselin, T., Perrier, C., Sainte-Marie, B., Rochette, R., \& Bernatchez, L. (2015). RAD genotyping reveals fine-scale genetic structuring and provides powerful population assignment in a widely distributed marine species, the American lobster (Homarus americanus). Molecular Ecology, 24, 3299-3315. https://doi.org/10.1111/ mec.13245

Bérénos, C., Ellis, P. A., Pilkington, J. G., \& Pemberton, J. M. (2014). Estimating quantitative genetic parameters in wild populations: A comparison of pedigree and genomic approaches. Molecular Ecology, 23, 3434-3451. https://doi.org/10.1111/mec.12827

Blomqvist, D., Pauliny, A., Larsson, M., \& Flodin, L.-Å. (2010). Trapped in the extinction vortex? Strong genetic effects in a declining vertebrate population. BMC Evolutionary Biology, 10, 33. https://doi. org/10.1186/1471-2148-10-33

Boulet, M., Couturier, S., Côté, S. D., Otto, R. D., \& Bernatchez, L. (2007). Integrative use of spatial, genetic, and demographic analyses for investigating genetic connectivity between migratory, montane, and sedentary caribou herds. Molecular Ecology, 16, 4223-4240. https:// doi.org/10.1111/j.1365-294X.2007.03476.x

Brambilla, A., Biebach, I., Bassano, B., Bogliani, G., \& von Hardenberg, A. (2015). Direct and indirect causal effects of heterozygosity on fitness-related traits in Alpine ibex. Proceedings of the Royal Society B, 282, 20141873. https://doi.org/10.1098/rspb.2014.1873

Brommer, J. E., Kekkonen, J., \& Wikström, M. (2015). Using heterozygosity-fitness correlations to study inbreeding depression in an isolated population of white-tailed deer founded by few individuals. Ecology and Evolution, 5, 357-367. https://doi.org/10.1002/ ece 3.1362

Catchen, J., Amores, A., Hohenlohe, P., Cresko, W., \& Postlethwait, J. H. (2011). Stacks: Building and genotyping loci de novo from short-read sequences. G3, 1, 171-182. https://doi.org/10.1534/g3.111.000240

Catchen, J., Hohenlohe, P. A., Bassham, S., Amores, A., \& Cresko, W. A. (2013). Stacks: An analysis tool set for population genomics. Molecular Ecology, 22, 3124-3140. https://doi.org/10.1111/mec.12354

Cecchi, F., Giacalone, G., \& Paci, G. (2016). Inbreeding depression in the Lizard canary breed estimated by pedigree analysis. Czech Journal of Animal Science, 61, 15-21. https://doi.org/10.17221/CJAS

Chapman, J. R., Nakagawa, S., Coltman, D. W., Slate, J., \& Sheldon, B. C. (2009). A quantitative review of heterozygosity-fitness correlations in animal populations. Molecular Ecology, 18, 2746-2765. https://doi. org/10.1111/j.1365-294X.2009.04247.x

Charlesworth, D., \& Charlesworth, B. (1987). Inbreeding depression and its evolutionary consequences. Annual Review of Ecology and Systematics, 18, 237-268. https://doi.org/10.1146/annur ev.es.18.110187.001321

Charmantier, A., Garant, D., \& Kruuk, L. E. B. (2014). Quantitative genetics in the wild, 1st ed. Oxford, UK: Oxford University Press. https://doi. org/10.1093/acprof:oso/9780199674237.001.0001

Coltman, D. W., \& Slate, J. (2003). Microsatellite measures of inbreeding: A meta-analysis. Evolution (N. Y.), 57, 971-983.

Couturier, S., Côté, S. D., Huot, J., \& Otto, R. D. (2009a). Body-condition dynamics in a northern ungulate gaining fat in winter. Canadian Journal of Zoology, 87, 367-378. https://doi.org/10.1139/Z09-020

Couturier, S., Côté, S. D., Otto, R. D., Weladji, R. B., \& Huot, J. (2009b). Variation in calf body mass in migratory caribou: The role of habitat, climate, and movements. Journal of Mammalogy, 90, 442-452. https ://doi.org/10.1644/07-MAMM-A-279.1

Couturier, S., Courtois, R., Crépeau, H., Rivest, L.-P., \& Luttich, S. (1996). Calving photocensus of the Rivière George caribou herd and comparison with an independent census. Rangifer, Special Issue no. 9, 283-296. https://doi.org/10.7557/2.16.4.1268

Couturier, S., Jean, D., Otto, R., \& Rivard, S. (2004). Demography of the migratory tundra caribou (Rangifer tarandus) of the Nord-du-Québec region and Labrador. Québec, QC: Ministère des Ressources naturelles, de la Faune et des Parcs, $68 \mathrm{p}$.

Couturier, S., Otto, R. D., Côté, S. D., Luther, G., \& Mahoney, S. P. (2010). Body size variations in caribou ecotypes and relationships with demography. Journal of Wildlife Management, 74, 395-404. https://doi. org/10.2193/2008-384

Da Silva, A., Gaillard, J. M., Yoccoz, N. G., Hewison, A. J., Galan, M., Coulson, T., ... Luikart, G. (2009). Heterozygosity-fitness correlations revealed by neutral and candidate gene markers in roe deer from a long-term study. Evolution (N. Y), 63, 403-417. 
Da Silva, A., Luikart, G., Yoccoz, N. G., Cohas, A., \& Allainé, D. (2006). Genetic diversity-fitness correlation revealed by microsatellite analyses in European alpine marmots (Marmota marmota). Conservation Genetics, 7, 371-382. https://doi.org/10.1007/ s10592-005-9048-y

David, P. (1998). Heterozygosity-fitness correlations: New perspectives on old problems. Heredity (Edinb), 80, 531-537. https://doi. org/10.1046/j.1365-2540.1998.00393.x

David, P., Delay, B., Berthou, P., \& Jarne, P. (1995). Alternative models for allozyme-associated heterosis in the marine bivalve Spisula ovalis. Genetics, 139, 1719-1726.

David, P., Pujol, B., Viard, F., Castellas, V., \& Goudet, J. (2007). Reliable selfing rate estimates from imperfect population genetic data. Molecular Ecology, 16, 2474-2487. https://doi. org/10.1111/j.1365-294X.2007.03330.x

Des Meules, P., \& Brassard, J. M. (1964). Inventaire préliminaire du Caribou (Rangifer tarandus caribou) d'un secteur de la Côte-Nord et du secteur Centre de l'Ungava. Québec, QC: Ministère du Tourisme, de la Chasse et de la Pêche Province du Québec, $468+$ XXIII p.

DeWoody, Y. D., \& DeWoody, J. A. (2005). On the estimation of genomewide heterozygosity using molecular markers. Journal of Heredity, 96 , 85-88. https://doi.org/10.1093/jhered/esi017

Fischer, M. C., Rellstab, C., Leuzinger, M., Roumet, M., Gugerli, F., Shimizu, K. K., ... Widmer, A. (2017). Estimating genomic diversity and population differentiation-An empirical comparison of microsatellite and SNP variation in Arabidopsis halleri. BMC Genomics, 18, 69. https:// doi.org/10.1186/s12864-016-3459-7

Forcada, J., \& Hoffman, J. I. (2014). Climate change selects for heterozygosity in a declining fur seal population. Nature, 511, 462-465. https ://doi.org/10.1038/nature13542

Gaillard, J.-M., Festa-Bianchet, M., Yoccoz, N. G., Loison, A., \& Toïgo, C. (2000). Temporal variation in fitness components and population dynamics of large herbivores. Annual Review of Ecology and Systematics, 31, 367-393. https://doi.org/10.1146/annurev.ecols ys.31.1.367

García-Navas, V., Cáliz-Campal, C., Ferrer, E. S., Sanz, J. J., \& Ortego, J. (2014). Heterozygosity at a single locus explains a large proportion of variation in two fitness-related traits in great tits: A general or a local effect? Journal of Evolutionary Biology, 27, 2807-2819. https:// doi.org/10.1111/jeb.12539

Gärke, C., Ytournel, F., Bed'hom, B., Gut, I., Lathrop, M., Weigend, S., \& Simianer, H. (2011). Comparison of SNPs and microsatellites for assessing the genetic structure of chicken populations. Animal Genetics, 43, 419-428.

Gholizadeh, M., \& Ghafouri-Kesbi, F. (2016). Inbreeding depression in growth traits of Baluchi sheep. Small Ruminant Research, 144, 184190. https://doi.org/10.1016/j.smallrumres.2016.09.012

Gilpin, M. E., \& Soulé, M. E. (1986). Minimum viable populations: Processes of species extinction. In M. E. Soulé (Ed.), Conservation biology: The science of scarcity and diversity (pp. 19-34). Sunderland, MA: Sinauer Associates.

Gosselin, T. (2017). Radiator: RADsea data exploration, manipulation and visualization using R. R package version 0.0.5. Retrieved from https ://github.com/thierrygosselin/radiator. https://doi.org/10.5281/ zenodo.154432

Guinand, B., Fustier, M. A., Labonne, M., Jourdain, E., Calvès, I., Quiniou, L., ... Laroche, J. (2013). Genetic structure and heterozygosity-fitness correlation in young-of-the-year sole (Solea solea L.) inhabiting three contaminated West-European estuaries. Journal of Sea Research, 80, 35-49. https://doi.org/10.1016/j.seares.2013.02.006

Herdegen, M., Nadachowska-Brzyska, K., Konowalik, A., Babik, W., \& Radwan, J. (2013). Heterozygosity, sexual ornament and body size in the crested newt. Journal of Zoology, 291, 146-153. https://doi. org/10.1111/jzo.12056
Hoffman, J. I., Simpson, F., David, P., Rijks, J. M., Kuiken, T., Thorne, M. A. S., ... Dasmahapatra, K. K. (2014). High-throughput sequencing reveals inbreeding depression in a natural population. Proceedings of the National Academy of Sciences of the United States of America, 111, 3775-3780. https://doi.org/10.1073/pnas.1318945111

Hogg, J. T., Forbes, S. H., Steele, B. M., \& Luikart, G. (2006). Genetic rescue of an insular population of large mammals. Proceedings of the Royal Society B, 273, 1491-1499. https://doi.org/10.1098/rspb.2006.3477

Holand, Ø., Askim, K. R., Roed, K. H., Weladji, R. B., Gjostein, H., \& Nieminen, M. (2007). No evidence of inbreeding avoidance in a polygynous ungulate: The reindeer (Rangifer tarandus). Biology Letters, 3 , 36-39. https://doi.org/10.1098/rsbl.2006.0575

Huisman, J., Kruuk, L. E. B., Ellis, P. A., Clutton-Brock, T., \& Pemberton, J. M. (2016). Inbreeding depression across the lifespan in a wild mammal population. Proceedings of the National Academy of Sciences of the United States of America, 113, 3585-3590. https://doi.org/10.1073/ pnas. 1518046113

Jombart, T. (2008). Adegenet: A R package for the multivariate analysis of genetic markers. Bioinformatics, 24, 1403-1405. https://doi. org/10.1093/bioinformatics/btn129

Jombart, T., Devillard, S., \& Balloux, F. (2010). Discriminant analysis of principal components: A new method for the analysis of genetically structured populations. BMC Genetics, 11, 94. https://doi. org/10.1186/1471-2156-11-94

Kaiser, S. A., Taylor, S. A., Chen, N., Sillett, T. S., Bondra, E. R., \& Webster, M. S. (2017). A comparative assessment of SNP and microsatellite markers for assigning parentage in a socially monogamous bird. Molecular Ecology Resources, 17, 183-193. https://doi. org/10.1111/1755-0998.12589

Kardos, M., Allendorf, F. W., \& Luikart, G. (2014). Evaluating the role of inbreeding depression in heterozygosity-fitness correlations: How useful are tests for identity disequilibrium? Molecular Ecology Resources, 14, 519-530. https://doi.org/10.1111/1755-0998.12193

Kardos, M., Taylor, H. R., Ellegren, H., Luikart, G., \& Allendorf, F. W. (2016). Genomics advances the study of inbreeding depression in the wild. Evolutionary Applications, 9, 1205-1218. https://doi. org/10.1111/eva.12414

Le Corre, M. R. V. (2016). Influence du climat, de la disponibilité des ressources et de la taille des populations sur la phénologie et les patrons de migration du caribou migrateur, Rangifer tarandus. Québec, QC: Université Laval.

Le Hénaff, D. (1976). Inventaire aérien des terrains de vêlage du caribou, dans la région du nord et au nord du territoire de la municipalité de la Baie James (mai-juin 1975). Québec, QC: Ministère du tourisme, de la chasse et de la pêche, Québec.

Lieutenant-Gosselin, M., \& Bernatchez, L. (2006). Local heterozygosity-fitness correlations with global positive effects on fitness in threespine stickleback. Evolution (N.Y.), 60, 1658-1668.

L'Italien, L., Weladji, R. B., Holand, Ø., Røed, K. H., Nieminen, M., \& Côté, S. D. (2012). Mating group size and stability in reindeer Rangifer tarandus: The effects of male characteristics, sex ratio and male age structure. Ethology, 118, 783-792. https://doi. $\operatorname{org} / 10.1111 /$ j.1439-0310.2012.02073.x

Liu, N., Chen, L., Wang, S., Oh, C., \& Zhao, H. (2005). Comparison of single-nucleotide polymorphisms and microsatellites in inference of population structure. BMC Genetics, 6, S26. https://doi. org/10.1186/1471-2156-6-S1-S26

Lohr, J. N., \& Haag, C. R. (2015). Genetic load, inbreeding depression, and hybrid vigor covary with population size: An empirical evaluation of theoretical predictions. Evolution (N.Y.), 69, 3109-3122.

Loison, A., Festa-Bianchet, M., Gaillard, J.-M., Jorgenson, J. T., \& Jullien, J.-M. (1999). Age-specific survival in five populations of ungulates: Evidence of senescence. Ecology, 80, 2539-2554. https://doi.org/10. 1890/0012-9658(1999)080[2539:ASSIFP]2.0.CO;2 
Lovatt, F. M., \& Hoelzel, A. R. (2014). Impact on reindeer (Rangifer tarandus) genetic diversity from two parallel population bottlenecks founded from a common source. Evolutionary Biology, 41, 240-250. https://doi.org/10.1007/s11692-013-9263-2

Luque, G. M., Vayssade, C., Facon, B., Guillemaud, T., Courchamp, F., \& Fauvergue, X. (2016). The genetic Allee effect: A unified framework for the genetics and demography of small populations. Ecosphere, 7, e01413. https://doi.org/10.1002/ecs2.1413

Martin, M. (2011). Cutadapt removes adapter sequences from highthroughput sequencing reads. EMBnet.journal, 17, 10-12. https://doi. org/10.14806/ej.17.1.200

Mastretta-Yanes, A., Arrigo, N., Alvarez, N., Jorgensen, T. H., Piñero, D., \& Emerson, B. C. (2015). Restriction site-associated DNA sequencing, genotyping error estimation and de novo assembly optimization for population genetic inference. Molecular Ecology Resources, 15, 28-41. https://doi.org/10.1111/1755-0998.12291

Mazerolle, M. J. (2017). AICcmodavg: Model selection and multimodel inference based on (Q)AIC(c). R package version 2.2-1. Retrieved from https $: / /$ cran.r-project.org/package=AICcmodavg

Miller, J. M., \& Coltman, D. W. (2014). Assessment of identity disequilibrium and its relation to empirical heterozygosity fitness correlations: A meta-analysis. Molecular Ecology, 23, 1899-1909. https://doi. org $/ 10.1111 / \mathrm{mec} .12707$

Miller, J. M., Malenfant, R. M., David, P., Davis, C. S., Poissant, J., Hogg, J. T., ... Coltman, D. W. (2014). Estimating genome-wide heterozygosity: Effects of demographic history and marker type. Heredity (Edinb), 112, 240-247. https://doi.org/10.1038/hdy.2013.99

Mitchell, J., Vitikainen, E. I. K., Wells, D. A., Cant, M. A., \& Nichols, H. J. (2017). Heterozygosity but not inbreeding coefficient predicts parasite burdens in the banded mongoose. Journal of Zoology, 302, 32-39. https://doi.org/10.1111/jzo.12424

Norén, K., Godoy, E., Dalén, L., Meijer, T., \& Angerbjörn, A. (2016). Inbreeding depression in a critically endangered carnivore. Molecular Ecology, 25, 3309-3318. https://doi.org/10.1111/mec.13674

Pachkowski, M., Côté, S. D., \& Festa-Bianchet, M. (2013). Spring-loaded reproduction: Effects of body condition and population size on fertility in migratory caribou (Rangifer tarandus). Canadian Journal of Zoology, 91, 473-479. https://doi.org/10.1139/cjz-2012-0334

Parker, G. R. (1981). Physical and reproductive characteristics of an expanding woodland caribou population (Rangifer tarandus caribou) in northern Labrador. Canadian Journal of Zoology, 59, 1929-1940. https ://doi.org/10.1139/z81-263

Pembleton, L. W., Cogan, N. O. I., \& Forster, J. W. (2013). StAMPP: An $R$ package for calculation of genetic differentiation and structure of mixed-ploidy level populations. Molecular Ecology Resources, 13, 946-952. https://doi.org/10.1111/1755-0998.12129

Perrier, C., Ferchaud, A.-L., Sirois, P., Thibault, I., \& Bernatchez, L. (2017). Do genetic drift and accumulation of deleterious mutations preclude adaptation? Empirical investigation using RADseq in a northern lacustrine fish. Molecular Ecology, 26, 6317-6335. https://doi. org/10.1111/mec.14361

Peterson, B. K., Weber, J. N., Kay, E. H., Fisher, H. S., \& Hoekstra, H. E. (2012). Double digest RADseq: An inexpensive method for de novo SNP discovery and genotyping in model and non-model species. PLoS ONE, 7, e37135. https://doi.org/10.1371/journal.pone.0037135

Queiros, J., Godinho, R., Lopes, S., Gortázar, C., de la Fuente, J., \& Alves, P. (2014). Effect of microsatellite selection on individual and population genetic inferences: An empirical study using cross-specific and species-specific amplifications. Molecular Ecology Resources, 15, 747-760.

Queirós, J., Vicente, J., Alves, P. C., de la Fuente, J., \& Gortazar, C. (2016). Tuberculosis, genetic diversity and fitness in the red deer, Cervus elaphus. Infection, Genetics and Evolution, 43, 203-212. https://doi. org/10.1016/j.meegid.2016.05.031
R Core Team. (2017). R: A language and environment for statistical computing. Vienna, Austria: R Foundation for Statistical Computing.

Silió, L., Barragán, C., Fernández, A. I., García-Casco, J., \& Rodríguez, M. C. (2016). Assessing effective population size, coancestry and inbreeding effects on litter size using the pedigree and SNP data in closed lines of the Iberian pig breed. Journal of Animal Breeding and Genetics, 133, 145-154. https://doi.org/10.1111/jbg.12168

Slate, J., David, P., Dodds, K. G., Veenvliet, B. A., Glass, B. C., Broad, T. E., \& McEwan, J. C. (2004). Understanding the relationship between the inbreeding coefficient and multilocus heterozygosity: Theoretical expectations and empirical data. Heredity (Edinb), 93, 255-265. https ://doi.org/10.1038/sj.hdy.6800485

Stoffel, M. A., Esser, M., Kardos, M., Humble, E., Nichols, H., David, P., \& Hoffman, J. I. (2016). inbreedR: An R package for the analysis of inbreeding based on genetic markers. Methods in Ecology and Evolution, 7, 1331-1339. https://doi.org/10.1111/2041-210X.12588

Szulkin, M., Bierne, N., \& David, P. (2010). Heterozygosity-fitness correlations: A time for reappraisal. Evolution (N.Y.), 64, 1202-1217.

Taillon, J., Barboza, P. S., \& Côté, S. D. (2013). Nitrogen allocation to offspring and milk production in a capital breeder. Ecology, 94, 18151827. https://doi.org/10.1890/12-1424.1

Taillon, J., Brodeur, V., Festa-Bianchet, M., \& Côté, S. D. (2011). Variation in body condition of migratory caribou at calving and weaning: Which measures should we use? Ecoscience, 18, 295-303. https:// doi.org/10.2980/18-3-3447

Tanaka, Y. (1997). Extinction of populations due to inbreeding depression with demographic disturbances. Researches on Population Ecology (Kyoto), 39, 57-66. https://doi.org/10.1007/BF02765250

Tanaka, Y. (1998). Theoretical aspects of extinction by inbreeding depression. Researches on Population Ecology (Kyoto), 40, 279-286. https ://doi.org/10.1007/BF02763459

Tanaka, Y. (2000). Extinction of populations by inbreeding depression under stochastic environments. Population Ecology, 42, 55-62.

Taylor, S. S., Jenkins, D. A., \& Arcese, P. (2012). Loss of Mhc and neutral variation in peary caribou: Genetic drift is not mitigated by balancing selection or exacerbated by Mhc allele distributions. PLoS ONE, 7, e36748. https://doi.org/10.1371/journal.pone.0036748

Velando, A., Barros, Á., \& Moran, P. (2015). Heterozygosity-fitness correlations in a declining seabird population. Molecular Ecology, 24, 1007-1018. https://doi.org/10.1111/mec.13092

Voegeli, B., Saladin, V., Wegmann, M., \& Richner, H. (2013). Heterozygosity is linked to the costs of immunity in nestling great tits (Parus major). Ecology and Evolution, 3, 4815-4827. https://doi. org/10.1002/ece3.854

Weir, B. S., \& Cockerham, C. C. (1973). Mixed self and random mating at two loci. Genetical Research, 21, 247-262. https://doi.org/10.1017/ S0016672300013446

Weir, B. S., \& Cockerham, C. C. (1984). Estimating F-statistics for the analysis of population structure. Evolution (N.Y.), 38, 1358-1370.

Wittmann, M. J., Stuis, H., \& Metzler, D. (2018). Genetic Allee effects and their interaction with ecological Allee effects. Journal of Animal Ecology, 87, 11-23. https://doi.org/10.1111/1365-2656.12598

Wright, S. (1931). Evolution in Mendelian populations. Genetics, 16, 97-159.

Wright, S. (1977). Evolution and the genetics of populations, Vol. 3. Chicago, IL: University of Chicago Press.

Yang, J., Lee, S. H., Goddard, M. E., \& Visscher, P. M. (2011). GCTA: A tool for genome-wide complex trait analysis. American Journal of Human Genetics, 88, 76-82. https://doi.org/10.1016/j.ajhg.2010.11.011

Yannic, G., St-Laurent, M. H., Ortego, J., Taillon, J., Beauchemin, A., Bernatchez, L., ... Côté, S. D. (2016). Integrating ecological and genetic structure to define management units for caribou in Eastern Canada. Conservation Genetics, 17, 437-453. https://doi.org/10.1007/ s10592-015-0795-0 
Zheng, X., Levine, D., Shen, J., Gogarten, S. M., Laurie, C., \& Weir, B. S. (2012). A high-performance computing toolset for relatedness and principal component analysis of SNP data. Bioinformatics, 28, 33263328. https://doi.org/10.1093/bioinformatics/bts606

\section{SUPPORTING INFORMATION}

Additional supporting information may be found online in the Supporting Information section at the end of the article.
How to cite this article: Gagnon M, Yannic G, Perrier C, Côté $\mathrm{SD}$. No evidence of inbreeding depression in fast declining herds of migratory caribou. J Evol Biol. 2019;00:1-14. https:// doi.org/10.1111/jeb.13533 